\title{
Tamanho de amostra de caracteres de genótipos de soja
}

\author{
Sample size of the characters in soybeans genotypes
}

\author{
Alberto Cargnelutti Filho ${ }^{\text {I* }}$ Dilson Henrique Ramos EvangelistaII \\ Elaine Cristine Piffer Gonçalves ${ }^{\mathrm{III}}$ Lindolfo Storck $^{\mathrm{I}}$
}

\section{RESUMO}

O objetivo deste trabalho foi estimar o tamanho de amostra necessária para avaliar caracteres de genótipos de soja (Glycine $\max$ L.) e verificar a variabilidade do tamanho de amostra entre genótipos e entre experimentos. Para tanto, 28 genótipos de soja foram avaliados em cinco experimentos conduzidos em Jaboticabal, Estado de São Paulo (latitude $21^{\circ} 15^{\prime} 22^{\prime \prime}$, longitude 4818'18" W e 595m de altitude), nos anos agrícolas de 2002 a 2005. Foi utilizado o delineamento de blocos ao acaso, com três repetições, e foram avaliados os caracteres altura de planta na maturação e de inserção de primeira vagem, número de nós por planta, de ramos por planta e de vagens por planta em seis plantas amostradas aleatoriamente na parcela. Há variabilidade da estimativa do tamanho de amostra entre genótipos quanto ao número de nós por planta e entre experimentos quanto à altura de planta na maturação, ao número de nós por planta, de ramos por planta e de vagens por planta. Para melhorar a precisão da avaliação de caracteres em plantas de soja, deve-se usar maior número de repetições $e$, pelo menos, 12 plantas por unidade experimental.

Palavras-chave: Glycine max L., planejamento experimental, amostragem, precisão experimental.

\section{ABSTRACT}

The aim of this research was to determine the sample size of characters in different soybeans (Glycine max L.) genotypes and to verify its variability among genotypes and experiments. Twenty-eight soybeans genotypes were evaluated in five experiments conducted in Jaboticabal, São Paulo State, Brazil (latitude 21 ${ }^{\circ} 15^{\prime} 22^{\prime \prime}$, longitude 48 ${ }^{\circ} 18^{\prime} 18^{\prime \prime}$ W, altitude 595m), in agricultural years from 2002 to 2005.
Randomized blocks design with three repetitions was installed to evaluate the following characters: plant height at maturity, height of first pod insertion, number of nodes per plant, number of branches per plant and number of pods per plant, in six plants sampled at random in each plot. It was found variability in the sample size among genotypes in relation to the number of nodes per plant. When the five experiments were compared, results also show variability of the sample size in relation to plant height at maturity, number of nodes per plant, number of branches per plant and number of pods per plant. To improve the experimental precision in the evaluation of characters in soybeans plants it is recommended to increase the number of repetitions and use, at least, twelve plants per plot.

Key words: Glycine max L., experimental planning, sampling, experimental precision.

\section{INTRODUÇÃO}

Em programas de melhoramento genético de soja, são avaliados diversos caracteres em vários genótipos visando à seleção de genótipos superiores. Para isso, nos experimentos, a mensuração em todas as plantas (indivíduos) da área útil da unidade experimental é adequada para estimar o caráter em avaliação. No entanto, é comum a medição em uma parte das plantas da unidade experimental (amostra) para minimizar o excesso de mão-de-obra, tempo, recursos financeiros e humanos. Assim, a amostra deve ser representativa das plantas da unidade experimental.

'Departamento de Fitotecnia, Centro de Ciências Rurais (CCR), Universidade Federal de Santa Maria (UFSM), 97105-900, Santa Maria, RS, Brasil. E-mail: cargnelutti@pq.cnpq.br.*Autor para correspondência.

"Curso de Estatística, Universidade Federal do Rio Grande do Sul (UFRGS), Porto Alegre, RS, Brasil.

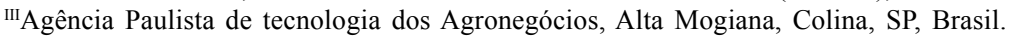


O tamanho de amostra é diretamente proporcional à variabilidade dos dados populacionais e ao grau de confiança desejado na estimativa e inversamente proporcional ao erro permitido, fixado $a$ priori pelo pesquisador. A relação entre os erros experimental (variação entre as parcelas) e amostral (variação entre as plantas dentro da parcela) permite inferir quanto à adequabilidade do aumento do número de repetições ou do tamanho de amostra para melhoria da precisão experimental (RAMALHO et al., 2000; BARBIN, 2003; STORCK et al., 2006). Quando o erro experimental é significativamente superior ao erro amostral, o aumento do número de repetições do experimento é adequado. Caso contrário, pode-se melhorar a precisão experimental aumentando-se, também, o número de indivíduos por parcela (tamanho de amostra) (STORCK et al., 2006).

$\mathrm{Na}$ área de planejamento experimental, pesquisas para estudar o tamanho de parcela e/ou tamanho de amostra e/ou número de repetições têm sido realizados em grandes culturas, tais como a soja (STORCK et al., 1982; ESTEFANEL et al., 1984; MARTIN et al., 2005c; MARTIN et al., 2007), o feijão (ESTEFANEL et al., 1996; CARGNELUTTI FILHO et al., 2008), o sorgo (LOPES et al., 2005; SILVA et al., 2005) e o milho (PALOMINO et al., 2000; MARTIN et al., 2005a; MARTIN et al., 2005b; STORCK et al., 2007). Além disso, estudos também têm sido realizados em olerícolas, tais como o pimentão (LÚCIO et al., 2003), o pepino (LORENTZ et al., 2004), a alface (MARODIM et al., 2000) e a abóbora italiana (SOUZA et al., 2002). Esses estudos, de maneira geral, evidenciam melhoria da precisão experimental com a apropriação do dimensionamento do planejamento experimental, obtido por meio da utilização de adequado tamanho e forma de parcelas, número de repetições e de amostras.

Em programas de melhoramento, é comum avaliar igual número de indivíduos na parcela (tamanho de amostra) para estimar parâmetros de diversos caracteres dos genótipos sob avaliação nos experimentos (locais, anos e épocas). Em caso de homogeneidade de variâncias entre caracteres, genótipos e experimentos, estimativas com mesma precisão são obtidas a partir de tamanho de amostra único. No entanto, em presença de heterogeneidade de variâncias entre caracteres, genótipos e experimentos, as estimativas obtidas a partir de um mesmo tamanho de amostra apresentam precisão diferenciada. Assim, para obtenção de estimativas com a mesma precisão, há necessidade de estimar um tamanho de amostra específico para caráter, genótipo e experimento.
A amostragem de seis plantas por parcela e a utilização de três repetições (blocos) para avaliar a altura de planta na maturação, a altura de inserção de primeira vagem, o número de nós por planta, o número de ramos por planta e o número de vagens por planta são comuns em ensaios de soja. No entanto, o tamanho de amostra desses caracteres é importante e pouco conhecido. Além disso, supõem-se presença de variabilidade entre caracteres, genótipos e experimentos. Visando melhorar a precisão experimental, o objetivo deste trabalho foi estimar o tamanho de amostra para avaliar caracteres de genótipos de soja (Glycine max (L.) Merril) e verificar sua variabilidade entre genótipos e entre experimentos (épocas e anos de avaliação).

\section{MATERIAL E MÉTODOS}

Vinte e oito genótipos de soja (Glycine max (L.) Merril) do programa de melhoramento do Departamento de Produção Vegetal, da Faculdade de Ciências Agrárias e Veterinárias, da Universidade Estadual Paulista (FCAV/UNESP), em Jaboticabal, São Paulo (SP), foram avaliados em cinco experimentos conduzidos em área experimental da FCAV/UNESP (latitude $21^{\circ} 15^{\prime} 22^{\prime \prime} \mathrm{S}$, longitude $48^{\circ} 18^{\prime} 18^{\prime \prime} \mathrm{W}$ e $595 \mathrm{~m}$ de altitude). Os experimentos foram conduzidos nos anos agrícolas de 2002 a 2005 com semeadura nos meses de maio ou junho (época da safrinha) e em novembro ou dezembro (época da safra). O delineamento experimental utilizado foi o de blocos ao acaso, com três repetições. As parcelas foram compostas de duas fileiras de $4 \mathrm{~m}$ de comprimento, espaçadas de $0,50 \mathrm{~m}$. As avaliações foram realizadas nos três metros centrais das linhas, desconsiderando-se $0,5 \mathrm{~m}$ em cada extremidade da fileira (área útil $=3 \mathrm{~m}^{2}$ ). A densidade de semeadura foi ajustada por meio de desbaste para 25 e 20 plantas por metro linear, respectivamente, para experimentos conduzidos na safrinha e na safra. O solo foi preparado com arações e gradagens, e a adubação de $250 \mathrm{~kg} \mathrm{ha}^{-1}$ da fórmula 420-20 (NPK) foi realizada no sulco da semeadura. Os tratos culturais, como controle de insetos e de plantas invasoras, foram realizados sempre que necessário, de maneira que a cultura não sofresse competição.

A altura de planta na maturação (APM) e de inserção de primeira vagem (APV) foi obtida por medições feitas em seis plantas, tomadas aleatoriamente, na área útil da parcela $\left(3 \mathrm{~m}^{2}\right)$. AAPM foi estimada por meio da distância, em centímetros, entre a superfície do solo e a extremidade da haste principal da planta e a APV, pela distância, em centímetros, entre a superfície do solo e o ponto de inserção de primeira vagem. Nessas seis plantas, foi contado, também, o 
número de nós por planta (NNP), avaliado pela contagem do número de nós do ramo principal, o número de ramos por planta (NRP) e o número de vagens por planta (NVP).

Os caracteres APM, APV, NNP, NRP e NVP, avaliados em cada experimento, foram submetidos à análise de variância e teste $\mathrm{F}$ a $5 \%$ de significância segundo o delineamento em blocos completos ao acaso com amostragem nas parcelas. A partir dos dados das seis plantas amostradas em cada unidade experimental (parcela) de cada genótipo, em cada experimento, foi estimado o tamanho de amostra (n) para os caracteres APM, APV, NNP, NRP e NVP, usando a expressão, $\mathrm{n}=\mathrm{t}_{\alpha / 2}^{2} \mathrm{CV}^{2} / \mathrm{D}^{2}$

conforme demonstrado em MARTIN et al. (2005b), em que o CV é o coeficiente de variação entre as seis plantas - em percentagem; D é a semi-amplitude do intervalo de confiança - em percentagem, para a média (estabeleceu-se $\mathrm{D}=5 \%, \mathrm{D}=10 \%, \mathrm{D}=20 \%, \mathrm{D}=30 \%$ e $\mathrm{D}=40 \%$ ); e t é o valor crítico da distribuição t, ao nível de 5\% (bilateral) de significância. Assim, foram obtidas 25 variáveis (tamanho de amostra) formadas pela combinação dos cinco caracteres (APM, APV, NNP, NRP e NVP) com os níveis de precisão de 5\% (D5), 10\%(D10), 20\%(D20), 30\%(D30) e 40\%(D40) da média estimada na unidade experimental.

Essas 25 variáveis (tamanho de amostra) foram submetidas à análise de variância conjunta, considerando genótipos e experimentos de efeito fixo e testes de $\mathrm{F}$ aproximado. As médias dos efeitos principais de genótipos e experimentos foram comparadas pelo teste de Scott Knott (RAMALHO et al., 2000) a 5\% de significância. As análises estatísticas foram realizadas com o auxílio do programa GENES (CRUZ, 2001) e do aplicativo Office Excel.

\section{RESULTADOS E DISCUSSÃO}

$\mathrm{O}$ efeito de genótipos foi significativo em relação à altura de planta na maturação (APM), ao número de nós por planta (NNP), ao número de ramos por planta (NRP) e ao número de vagens por planta (NVP) em $60 \%, 60 \%$, 40\% e $60 \%$ dos experimentos, respectivamente, evidenciando presença de variabilidade genética e possibilidade de identificação de genótipos superiores. Por outro lado, não houve efeito de genótipos quanto à altura de inserção de primeira vagem (APV) em nenhum dos cinco experimentos, o que revela ausência de variabilidade no germoplasma avaliado (Tabela 1).

Em 14 dos 25 casos (cinco caracteres $\times$ cinco experimentos) não houve efeito significativo de genótipos. Além disso, entre os 14, oito casos (57\%) estiveram associados à presença de interação bloco×genótipo (erro experimental), evidenciando a necessidade de aumentar o número de repetições para melhorar a discriminação dos genótipos (Tabela 1). Resultados semelhantes foram encontrados para caracteres de feijão(CARGNELUTTIFILHO et al., 2008). MARTIN et al. (2005) concluíram que, para as cultivares de soja ('BRS 137' e 'Fepagro-RS 10'), o número de repetições que confere uma precisão adequada é igual a sete, e o tamanho ótimo de parcela é de $3,96 \mathrm{~m}^{2}$.

O erro experimental (variação entre parcelas) foi significativo em $80 \%, 40 \%, 60 \%, 40 \%$ e $40 \%$ dos experimentos, respectivamente, em relação aos caracteres APM, APV, NNP, NRP e NVP (amostragem foi eficiente). Nesses 13 casos, o aumento do número de repetições é apropriado para melhorar a precisão experimental (BARBIN, 2003; STORCK et al., 2006). Já nos demais casos (12), o efeito do erro experimental não foi significativo, revelando que a amostragem foi ineficiente. Como conseqüência, o aumento do tamanho da amostra é adequado para a melhoria da precisão experimental (STORCK et al., 2006). Portanto, o redimensionamento do uso de três repetições (blocos) e a amostragem de seis plantas por parcela para avaliar os caracteres APM, APV, NNP, NRP e NVP são convenientes para melhorar a precisão experimental.

Experimentos de campo com coeficiente de variação experimental (CVe) inferior a $10 \%$, entre $10 \%$ e $20 \%$, entre $20 \%$ e $30 \%$ e superiores a $30 \%$ são classificados, respectivamente, como de alta, média, baixa e muito baixa precisão experimental por GOMES (1990). Para a cultura de soja, LÚCIO et al. (1999) apresentam a seguinte classificação do CVe: muito baixo $(\mathrm{CVe} \leq 5 \%)$, baixo $(5 \%<\mathrm{CVe}<9 \%)$, médio $(9 \% \leq$ $\mathrm{CVe} \leq 15 \%)$, alto $(15 \%<\mathrm{CVe} \leq 19 \%)$ e muito alto (CVe $>19 \%$ ), conferindo, respectivamente, muito alta, alta, média, baixa e muito baixa precisão experimental. Assim, 92\% dos casos (cinco caracteres $\mathrm{x}$ cinco experimentos) apresentaram CVe superior a 15\%, o que confere baixa e muito baixa precisão experimental (LÚCIO et al., 1999). Esse fato pode levar à seleção inadequada de genótipos. O coeficiente de variação experimental (CVe) médio dos cinco experimentos foi $24,97 \%, 24,08 \%$, $23,70 \%, 55,46 \%$ e $36,62 \%$, respectivamente, para os caracteres APM, APV, NNP, NRP e NVP. Já o coeficiente de variação amostral (CVa) médio dos cinco experimentos foi $12,91 \%, 21,09 \%, 15,84 \%, 42,56 \%$ e $25,83 \%$, respectivamente, para os caracteres APM, APV, NNP, NRP e NVP. Esses resultados evidenciam menor variabilidade dentro de unidades experimentais do que entre unidades experimentais e mostram, de maneira geral, a necessidade de maior número de repetições para melhoria da precisão experimental (BARBIN, 2003). 
Tabela 1 - Graus de liberdade (GL) e quadrado médio para as causas de variação da análise de variância, média, coeficiente de variação experimental (CVe) e coeficiente de variação amostral (CVa) para caracteres de plantas de 28 genótipos de soja avaliados em cinco experimentos.

\begin{tabular}{|c|c|c|c|c|c|c|}
\hline \multirow{2}{*}{$\begin{array}{l}\text { Causas de } \\
\text { variação }\end{array}$} & \multirow[b]{2}{*}{ GL } & \multicolumn{5}{|c|}{-10.-- Experimento ${ }^{(1)}$-.. } \\
\hline & & 1 & 2 & 3 & 4 & 5 \\
\hline & & \multicolumn{5}{|c|}{ 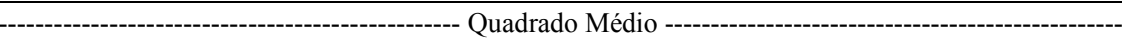 } \\
\hline & & \multicolumn{5}{|c|}{-------------------------------------------Altura de planta na maturação------------------------------------------ } \\
\hline Bloco & 2 & $135,93^{\text {ns }}$ & $1327,64^{\mathrm{ns}}$ & $474,02^{\text {ns }}$ & $227,88^{\mathrm{ns}}$ & $49,53^{\text {ns }}$ \\
\hline Genótipo & 27 & $319,48 *$ & $804,11^{*}$ & $922,77^{\text {ns }}$ & $830,13 *$ & $257,74^{\mathrm{ns}}$ \\
\hline Erro exp & 54 & $171,27^{\mathrm{ns}}$ & $424,78^{*}$ & $987,68 *$ & $226,18^{*}$ & $202,22 *$ \\
\hline Erro am & 420 & 174,75 & 48,72 & 77,30 & 86,42 & 134,75 \\
\hline Média & & 79,89 & 67,59 & 75,56 & 81,14 & 79,67 \\
\hline $\mathrm{CVe}(\%)$ & - & 16,38 & 30,49 & 41,59 & 18,54 & 17,85 \\
\hline $\mathrm{CVa}(\%)$ & - & 16,55 & 10,33 & 11,64 & 11,46 & 14,57 \\
\hline Bloco & 2 & \multicolumn{5}{|c|}{ 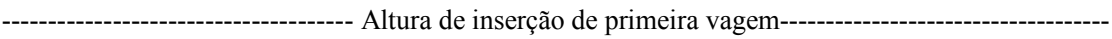 } \\
\hline $\begin{array}{l}\text { Bloco } \\
\text { Genótipo }\end{array}$ & $\begin{array}{l}2 \\
27\end{array}$ & $\begin{array}{l}0,05 \\
5,64^{\mathrm{ns}}\end{array}$ & $\begin{array}{l}31,01 \\
11,12^{\mathrm{ns}}\end{array}$ & $\begin{array}{l}11,80 \\
23,68^{\mathrm{ns}}\end{array}$ & $\begin{array}{l}5,99 \\
7,30^{\text {ns }}\end{array}$ & $8,61^{\text {ns }}$ \\
\hline $\begin{array}{l}\text { Genotipo } \\
\text { Erro exp }\end{array}$ & $\begin{array}{l}21 \\
54\end{array}$ & $\begin{array}{l}5,04 \\
5,53^{\text {ns }}\end{array}$ & $\begin{array}{l}11,12 \\
11,24 *\end{array}$ & $\begin{array}{l}23,08 \\
16,25 *\end{array}$ & $6.00^{\text {ns }}$ & $\begin{array}{l}8,01 \\
6,56^{\mathrm{ns}}\end{array}$ \\
\hline Erro am & 420 & 6,68 & 5,84 & 6,81 & $\begin{array}{l}0,00 \\
6,82\end{array}$ & $\begin{array}{l}0,50 \\
7,02\end{array}$ \\
\hline Média & & 12,01 & 12,14 & 12,69 & 11,99 & 12,19 \\
\hline $\mathrm{CVe}(\%)$ & - & 19,58 & 27,60 & 31,76 & 20,43 & 21,01 \\
\hline $\mathrm{CVa}(\%)$ & - & 21,52 & 19,89 & 20,56 & 21,77 & 21,73 \\
\hline & & \multicolumn{5}{|c|}{ 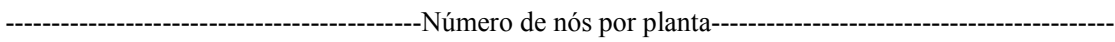 } \\
\hline Bloco & 2 & $8,93^{\mathrm{ns}}$ & $4,92^{\mathrm{ns}}$ & $86,80^{*}$ & $12,55^{\mathrm{ns}}$ & $4,47^{\mathrm{ns}}$ \\
\hline Genótipo & 27 & $15,07^{*}$ & $9,06^{\mathrm{ns}}$ & $36,22^{\mathrm{ns}}$ & $121,18^{*}$ & $14,78^{*}$ \\
\hline Erro exp & 54 & $3,87^{\mathrm{ns}}$ & $8,52 *$ & $23,77^{*}$ & $9,77 *$ & $7,10^{\mathrm{ns}}$ \\
\hline Erro am & 420 & 10,56 & 1,49 & 2,43 & 3,11 & 7,39 \\
\hline Média & & 12,94 & 10,33 & 15,39 & 11,78 & 15,84 \\
\hline CVe (\%) & - & 15,21 & 28,26 & 31,67 & 26,53 & 16,82 \\
\hline CVa (\%) & - & 25,12 & 11,81 & 10,13 & 14,96 & 17,16 \\
\hline & & \multicolumn{5}{|c|}{-------------------------------------------Número de ramos por planta------------------------------------------- } \\
\hline Bloco & 2 & $5,20^{\mathrm{ns}}$ & $9,94^{\mathrm{ns}}$ & $53,39 *$ & $0,19^{\mathrm{ns}}$ & $2,70^{\mathrm{ns}}$ \\
\hline Genótipo & 27 & $7,60^{*}$ & $12,06^{*}$ & $12,13^{\text {ns }}$ & $2,74^{\mathrm{ns}}$ & $3,23^{\mathrm{ns}}$ \\
\hline Erro exp & 54 & $4,26^{\mathrm{ns}}$ & $5,51^{*}$ & $10,50^{*}$ & $2,00^{\mathrm{ns}}$ & $2,91^{\mathrm{ns}}$ \\
\hline Erro am & 420 & 3,35 & 1,71 & 3,20 & 2,50 & 2,68 \\
\hline Média & & 4,07 & 3,17 & 5,01 & 3,40 & 3,69 \\
\hline CVe (\%) & - & 50,76 & 74,07 & 64,62 & 41,57 & 46,26 \\
\hline CVa (\%) & - & 45,01 & 41,32 & 35,68 & 46,44 & 44,36 \\
\hline Bloco & 2 & \multicolumn{4}{|c|}{ 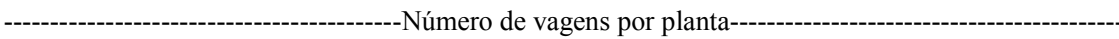 } & $2,59^{\text {ns }}$ \\
\hline Genótipo & 27 & $275,40^{\mathrm{ns}}$ & $319,76^{*}$ & $1053,88^{\mathrm{ns}}$ & $437,73 *$ & $545,39 *$ \\
\hline Erro exp & 54 & $215,07^{\mathrm{ns}}$ & $133,45^{*}$ & $1150,19 *$ & $141,47^{\mathrm{ns}}$ & $112,40^{\mathrm{ns}}$ \\
\hline Erro am & 420 & 164,73 & 48,75 & 318,12 & 247,76 & 213,15 \\
\hline Média & & 48,96 & 22,11 & 43,12 & 99,75 & 102,91 \\
\hline $\mathrm{CVe}(\%)$ & - & 29,95 & 52,25 & 78,66 & 11,92 & 10,30 \\
\hline $\mathrm{CVa}(\%)$ & - & 26,21 & 31,58 & 41,37 & 15,78 & 14,19 \\
\hline
\end{tabular}

(1) Experimentos: 1) semeadura em maio de 2002; 2) semeadura em maio de 2003; 3) semeadura em novembro 2003; 4) semeadura em novembro 2004; e 5) semeadura em dezembro 2004 . ${ }^{(2)} *$ Efeito significativo pelo teste $\mathrm{F}$ em nível de $5 \%$ de probabilidade de erro. ${ }^{\text {ns }}$ Nãosignificativo.

Ciência Rural, v.39, n.4, jul, 2009. 
Entre os caracteres, o NRP e NVP apresentam, nessa ordem, maiores valores médios de CVe e CVa, o que comprova maior variabilidade desses caracteres em relação aos demais (APM, APV, NNP), tanto entre parcelas, quanto entre plantas dentro de parcelas. Os resultados evidenciam ainda que, para esses caracteres (NRP e NVP), haveria necessidade de maior número de repetições e de tamanho de amostra quando comparados aos demais caracteres (APM, APV, NNP). De maneira geral, os resultados sugerem a necessidade de rever as técnicas experimentais utilizadas para a soja, como a adequação do planejamento quanto ao tamanho da parcela, ao número de repetições e ao tamanho de amostra (STORCK et al., 1982; ESTEFANEL et al., 1984; MARTIN et al., 2005c; MARTIN et al., 2007), pois são importantes para maior precisão nas estimativas.

Em relação ao tamanho de amostra dos caracteres APM, APV, NNP, NRP e NVP, não houve interação genótipo $\times$ experimento, indicando que o comportamento dos genótipos não varia com os experimentos (Tabela 2). Já o efeito de genótipos foi significativo $(\mathrm{P} \leq 0,05)$ apenas em relação ao NNP, e o efeito de experimentos foi significativo (em relação aos caracteres APM, NNP, NRP e NVP (Tabela 2), o que demonstra variabilidade do tamanho de amostra entre genótipos e entre experimentos.

Quanto ao tamanho de amostra para o NNP, os genótipos foram separados em dois grupos por meio do teste de Scott Knott (Tabela 3). Os genótipos 20, 25, 26,27 e 28 compõem o grupo com maior variabilidade entre as plantas dentro da parcela, necessitando maior número de plantas para estimativa com uma mesma precisão, quando comparado esse grupo aos demais 23 genótipos do grupo dois. Variabilidade da estimativa do tamanho de amostra foi constatada em três cultivares de soja ('IAS-2', 'Bragg' e 'Hardee') quanto aos caracteres altura de planta, altura de inserção do primeiro legume, diâmetro do caule, número de nós no caule, número de legumes no caule, número de grãos no caule e peso de grão no caule (ESTEFANEL et al., 1984) entre 14 cultivares de feijão quanto à altura de inserção de última vagem, ao número de vagens por planta e ao número de sementes por planta (CARGNELUTTI FILHO et al., 2008), entre as cultivares de feijão 'Iraí' e 'Macanudo' (ESTEFANEL et al., 1996) e em caracteres de genótipos de milho (MARTIN et al., 2005b; STORCK et al., 2007).

Quanto aos caracteres APM, APV, NRP e NVP, o tamanho de amostra (número de plantas) médio representa todos os genótipos. A amostragem de três, oito, 32 e 13 plantas por unidade experimental, respectivamente, para APM, APV, NRP e NVP, resultam em estimativas da média de genótipo com uma precisão de 20\% da média (D20) (Tabela 3). Esses resultados confirmam as inferências anteriores em relação ao maior tamanho de amostra necessário para os caracteres NRP

Tabela 2 - Graus de liberdade (GL), valor calculado do teste F e respectivo p-valor (entre parênteses) das causas de variação, coeficiente de variação $(\mathrm{CV})$ e relação entre o maior e o menor quadrado médio residual entre os experimentos $\left(\mathrm{QMr}^{+} / \mathrm{QMr}^{-}\right)$da análise de variância conjunta em relação aos tamanhos de amostra de caracteres avaliados em plantas de 28 genótipos de soja obtidas em cinco experimentos

\begin{tabular}{|c|c|c|c|c|c|c|}
\hline \multirow{2}{*}{ Caráter } & \multirow[b]{2}{*}{ Bloco/Experimento } & \multirow[b]{2}{*}{ Genótipo (G) } & \multirow[b]{2}{*}{ Experimento (E) } & \multirow[b]{2}{*}{ GxE } & \multirow{2}{*}{ CV $(\%)$} & \multirow{2}{*}{$\mathrm{QMr}^{+} / \mathrm{QMr}$} \\
\hline & & & & & & \\
\hline & $\mathrm{GL}=10$ & $\mathrm{GL}=27$ & $\mathrm{GL}=4$ & $\mathrm{GL}=108$ & & \\
\hline $\begin{array}{l}\text { Altura de planta na } \\
\text { maturação }\end{array}$ & $\begin{array}{l}1,290 \\
(0,2356)\end{array}$ & $\begin{array}{c}0,790 \\
(0,7645)\end{array}$ & $\begin{array}{l}25,02647 \\
(0,00003)\end{array}$ & $\begin{array}{c}1,154 \\
(0,1790)\end{array}$ & 67,53 & 5,0697 \\
\hline $\begin{array}{l}\text { Altura de inserção de } \\
\text { primeira vagem }\end{array}$ & $\begin{array}{l}1,235 \\
(0,2688)\end{array}$ & $\begin{array}{c}0,848 \\
(0,6858)\end{array}$ & $\begin{array}{c}1,12624 \\
(0,39761)\end{array}$ & $\begin{array}{c}1,112 \\
(0,2467)\end{array}$ & 60,44 & 1,3399 \\
\hline $\begin{array}{l}\text { Número de nós por } \\
\text { planta }\end{array}$ & $\begin{array}{l}0,745 \\
(0,6818)\end{array}$ & $\begin{array}{c}2,666 \\
(0,0000)\end{array}$ & $\begin{array}{c}170,18674 \\
(0,00000)\end{array}$ & $\begin{array}{c}1,223 \\
(0,0991)\end{array}$ & 63,51 & 6,0492 \\
\hline $\begin{array}{l}\text { Número de ramos por } \\
\text { planta }\end{array}$ & $\begin{array}{l}0,441 \\
(0,9256)\end{array}$ & $\begin{array}{c}1,294 \\
(0,1558)\end{array}$ & $\begin{array}{l}12,29235 \\
(0,00071)\end{array}$ & $\begin{array}{c}0,955 \\
(0,6021)\end{array}$ & 81,67 & 4,1221 \\
\hline $\begin{array}{l}\text { Número de vagens por } \\
\text { planta }^{(1)}\end{array}$ & $\begin{array}{l}0,2331 \\
(0,9923)\end{array}$ & $\begin{array}{c}0,4601 \\
(0,9883)\end{array}$ & $\begin{array}{l}107,9440 \\
(0,0000)\end{array}$ & $\begin{array}{c}0,9410 \\
(0,5826)\end{array}$ & 145,56 & 61,9483 \\
\hline
\end{tabular}

* Significativo a $5 \%$ de probabilidade de erro (aproximado). ${ }^{\text {ns }}$ Não-significativo. ${ }^{(1)}$ Graus de liberdade de GxE $=46$ e do resíduo $=98$ devido à correção. 
Tabela 3 - Tamanho de amostra (número de plantas) de 28 genótipos de soja para uma semi-amplitude do intervalo com $95 \%$ de confiança, igual a 5\% (D5), 10\% (D10), 20\% (D20), 30\% (D30) e 40\% (D40) da média em relação aos caracteres altura de planta na maturação (APM), altura de inserção de primeira vagem (APV) e número de nós por planta (NNP) avaliados em cinco experimentos.

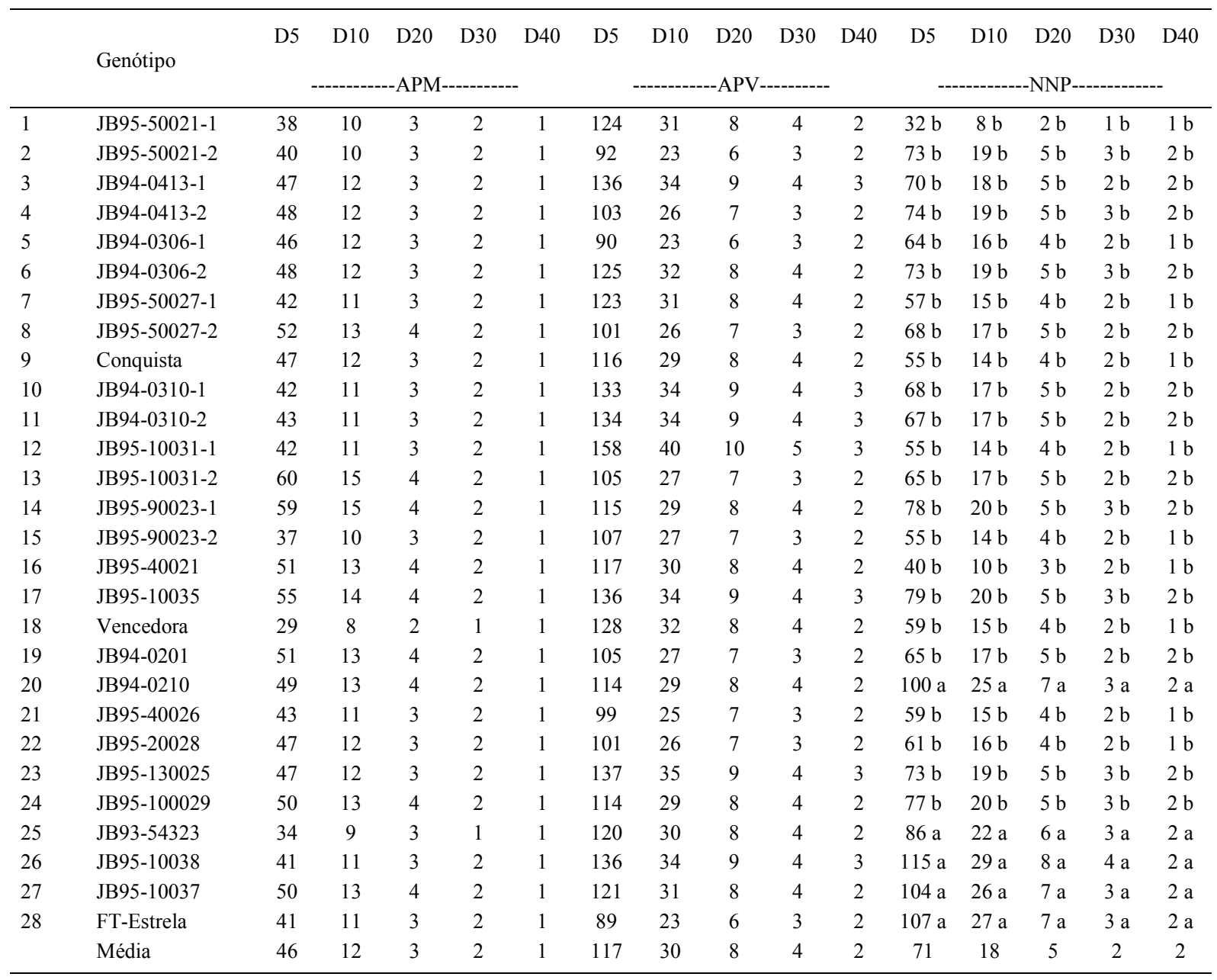

* Médias não seguidas de mesma letra diferem pelo teste de Scott Knott em nível de 5\% de probabilidade de erro (aproximado). Valores iguais com letras diferentes devido ao arredondamento sem nenhuma casa decimal.

e NVP em relação aos demais, para uma mesma precisão e ainda que haja variabilidade do tamanho de amostra entre os caracteres, conforme constatado em soja por ESTEFANEL et al. (1984), em feijão por CARGNELUTTI FILHO et al. (2008), em milho por MARTIN et al. (2005b) e STORCK et al. (2007).

Por meio do teste de Scott Knott, em relação ao tamanho de amostra entre os cinco experimentos, houve formação de três, quatro, dois e quatro grupos, respectivamente, quanto aos caracteres APM, NNP, NRP e NVP. A variabilidade das condições ambientais, específicas de cada experimento, pode explicar tais resultados. Já o tamanho de amostra para estimar a APV não diferiu entre os experimentos. Esses resultados denotam presença de variabilidade do tamanho de amostra entre os experimentos, como constatado em soja (ESTEFANEL et al., 1984), em feijão (CARGNELUTTI FILHO et al., 2008), em pimentão (LÚCIO et al., 2003), em pepino (LORENTZ et al., 2004) e em abóbora italiana (SOUZA et al., 2002).

De maneira geral, os resultados evidenciam que, do ponto de vista de técnicas experimentais, os pesquisadores devem considerar o caráter, o genótipo e o experimento ao dimensionar o tamanho de amostra para uma avaliação precisa desses caracteres de soja. A área útil da parcela $\left(3 \mathrm{~m}^{2}\right)$ tem aproximadamente $150 \mathrm{e}$ 120 plantas, respectivamente, para a época da safra e safrinha. Então, estimativas com precisão inferior a 5\%, de modo geral, são impraticáveis.

Ciência Rural, v.39, n.4, jul, 2009. 
Considerando que o tamanho de amostra médio contempla, em geral, um maior número de casos, poder-se-ia optar pelo maior número médio de tamanho de amostra dentre os caracteres observados. Nesse caso, o tamanho de amostra para NRP seria de oito, 15 e 32 plantas por parcela para uma precisão de $40 \%$ (D40), 30\% (D30) e 20\% (D20), respectivamente (Tabelas 3, 4 e 5). Padronizando o mesmo tamanho de amostra para avaliar esses caracteres, maior precisão nas estimativas é obtida em relação à $\mathrm{APM}$, diminuindo gradativamente na seguinte ordem: NNP, APV, NVP e NRP. Em amostragem de 12 plantas por unidade experimental (dobro da utilizada), a precisão obtida será, aproximadamente, de 30\% (D30) para o NRP, de 20\% (D20) para NVP eAPV, 15\% para NNP e 10\% (D10) para APM (Tabelas 3 e 4).

\section{CONCLUSÕES}

Há variabilidade da estimativa do tamanho de amostra entre genótipos quanto ao número de nós por planta e entre experimentos quanto à altura de planta na maturação, ao número de nós por planta, ao número de ramos por planta e ao número de vagens por planta. Para melhorar a precisão da avaliação de caracteres em plantas de soja, deve-se usar maior número de repetições e, pelo menos, 12 plantas por unidade experimental.

\section{AGRADECIMENTOS}

Ao Conselho Nacional de Desenvolvimento Científico e Tecnológico (CNPq), pela concessão de bolsa de Produtividade em Pesquisa a Alberto Cargnelutti Filho e a Lindolfo Storck.

Tabela 4 - Tamanho de amostra (número de plantas) de 28 genótipos de soja para uma semi-amplitude do intervalo com $95 \%$ de confiança, igual a 5\% (D5), 10\% (D10), 20\% (D20), 30\% (D30) e 40\% (D40) da média em relação aos caracteres número de ramos por planta (NRP) e número de vagens por planta (NVP) avaliados em cinco experimentos.

\begin{tabular}{|c|c|c|c|c|c|c|c|c|c|c|c|}
\hline & \multirow{2}{*}{ Genótipo } & D5 & D10 & D20 & D30 & D40 & D5 & D10 & D20 & D30 & D40 \\
\hline & & \multicolumn{5}{|c|}{--------------------------NRP-------------------------- } & \multicolumn{5}{|c|}{ 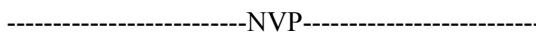 } \\
\hline 1 & JB95-50021-1 & 464 & 116 & 29 & 13 & 8 & 246 & 62 & 16 & 7 & 4 \\
\hline 2 & JB95-50021-2 & 422 & 106 & 27 & 12 & 7 & 181 & 46 & 12 & 6 & 3 \\
\hline 3 & JB94-0413-1 & 619 & 155 & 39 & 18 & 10 & 158 & 40 & 10 & 5 & 3 \\
\hline 4 & JB94-0413-2 & 374 & 94 & 24 & 11 & 6 & 203 & 51 & 13 & 6 & 4 \\
\hline 5 & JB94-0306-1 & 446 & 112 & 28 & 13 & 7 & 208 & 52 & 13 & 6 & 4 \\
\hline 6 & JB94-0306-2 & 640 & 160 & 40 & 18 & 10 & 125 & 32 & 8 & 4 & 2 \\
\hline 7 & JB95-50027-1 & 490 & 123 & 31 & 14 & 8 & 127 & 32 & 8 & 4 & 2 \\
\hline 8 & JB95-50027-2 & 663 & 166 & 42 & 19 & 11 & 262 & 66 & 17 & 8 & 5 \\
\hline 9 & Conquista & 563 & 141 & 36 & 16 & 9 & 191 & 48 & 12 & 6 & 3 \\
\hline 10 & JB94-0310-1 & 695 & 174 & 44 & 20 & 11 & 173 & 44 & 11 & 5 & 3 \\
\hline 11 & JB94-0310-2 & 516 & 129 & 33 & 15 & 9 & 182 & 46 & 12 & 6 & 3 \\
\hline 12 & JB95-10031-1 & 569 & 143 & 36 & 16 & 9 & 179 & 45 & 12 & 5 & 3 \\
\hline 13 & JB95-10031-2 & 437 & 110 & 28 & 13 & 7 & 256 & 64 & 16 & 8 & 4 \\
\hline 14 & JB95-90023-1 & 528 & 132 & 33 & 15 & 9 & 280 & 70 & 18 & 8 & 5 \\
\hline 15 & JB95-90023-2 & 675 & 169 & 43 & 19 & 11 & 109 & 28 & 7 & 4 & 2 \\
\hline 16 & JB95-40021 & 530 & 133 & 34 & 15 & 9 & 235 & 59 & 15 & 7 & 4 \\
\hline 17 & JB95-10035 & 424 & 106 & 27 & 12 & 7 & 214 & 54 & 14 & 6 & 4 \\
\hline 18 & Vencedora & 521 & 131 & 33 & 15 & 9 & 328 & 82 & 21 & 10 & 6 \\
\hline 19 & JB94-0201 & 412 & 103 & 26 & 12 & 7 & 194 & 49 & 13 & 6 & 4 \\
\hline 20 & JB94-0210 & 840 & 210 & 53 & 24 & 14 & 211 & 53 & 14 & 6 & 4 \\
\hline 21 & JB95-40026 & 523 & 131 & 33 & 15 & 9 & 257 & 65 & 17 & 8 & 5 \\
\hline 22 & JB95-20028 & 492 & 123 & 31 & 14 & 8 & 172 & 43 & 11 & 5 & 3 \\
\hline 23 & JB95-130025 & 363 & 91 & 23 & 11 & 6 & 215 & 54 & 14 & 6 & 4 \\
\hline 24 & JB95-100029 & 438 & 110 & 28 & 13 & 7 & 165 & 42 & 11 & 5 & 3 \\
\hline 25 & JB93-54323 & 401 & 101 & 26 & 12 & 7 & 197 & 50 & 13 & 6 & 4 \\
\hline 26 & JB95-10038 & 488 & 122 & 31 & 14 & 8 & 201 & 51 & 13 & 6 & 4 \\
\hline 27 & JB95-10037 & 319 & 80 & 20 & 9 & 5 & 221 & 56 & 14 & 7 & 4 \\
\hline \multirow[t]{2}{*}{28} & FT-Estrela & 309 & 78 & 20 & 9 & 5 & 114 & 29 & 8 & 4 & 2 \\
\hline & Média & 506 & 127 & 32 & 15 & 8 & 200 & 50 & 13 & 6 & 4 \\
\hline
\end{tabular}

Ciência Rural, v.39, n.4, jul, 2009. 
Tabela 5 - Tamanho de amostra (número de plantas) de 28 genótipos de soja para uma semi-amplitude do intervalo com $95 \%$ de confiança, igual a $5 \%(\mathrm{D} 5), 10 \%$ (D10), 20\% (D20), 30\% (D30) e 40\% (D40) da média em relação aos caracteres altura de planta na maturação, altura de inserção de primeira vagem, número de nós por planta, número de ramos por planta e número de vagens por planta avaliadas em cinco experimentos.

\begin{tabular}{|c|c|c|c|c|c|c|c|c|c|c|c|c|}
\hline \multicolumn{3}{|c|}{ Experimento } & \multicolumn{5}{|c|}{--------Altura de planta na maturação-------- } & \multicolumn{5}{|c|}{------Altura de inserção de primeira vagem------ } \\
\hline & Época & Mês/Ano & $\mathrm{D} 5^{*}$ & $\mathrm{D} 10$ & D20 & D30 & D40 & D5 & $\mathrm{D} 10$ & $\mathrm{D} 20$ & D30 & D40 \\
\hline 1 & Safrinha & Maio/2002 & $74 \mathrm{a}$ & $19 \mathrm{a}$ & $5 \mathrm{a}$ & $3 \mathrm{a}$ & $2 \mathrm{a}$ & 120 & 30 & 8 & 4 & 2 \\
\hline 2 & Safrinha & Maio/2003 & $27 \mathrm{c}$ & $7 \mathrm{c}$ & $2 \mathrm{c}$ & $1 \mathrm{c}$ & $1 \mathrm{c}$ & 102 & 26 & 7 & 3 & 2 \\
\hline 3 & Safra & Novembro/2003 & $36 \mathrm{c}$ & $9 \mathrm{c}$ & $3 \mathrm{c}$ & $1 \mathrm{c}$ & $1 \mathrm{c}$ & 117 & 30 & 8 & 4 & 2 \\
\hline 4 & Safra & Novembro/2004 & $35 \mathrm{c}$ & $9 \mathrm{c}$ & $3 \mathrm{c}$ & $1 \mathrm{c}$ & $1 \mathrm{c}$ & 125 & 32 & 8 & 4 & 2 \\
\hline \multirow[t]{4}{*}{5} & Safra & Dezembro/2004 & $56 \mathrm{~b}$ & $14 \mathrm{~b}$ & $4 \mathrm{~b}$ & $2 \mathrm{~b}$ & $1 \mathrm{~b}$ & 122 & 31 & 8 & 4 & 2 \\
\hline & Média & & 46 & 12 & 3 & 2 & 1 & 117 & 30 & 8 & 4 & 2 \\
\hline & & & \multicolumn{5}{|c|}{----------Número de nós por planta--------- } & \multicolumn{5}{|c|}{---------Número de ramos por planta--------- } \\
\hline & Época & Mês/Ano & D5 & D10 & D20 & D30 & D40 & D5 & $\mathrm{D} 10$ & D20 & D30 & D40 \\
\hline 1 & Safrinha & Maio/2002 & $162 \mathrm{a}$ & $41 \mathrm{a}$ & $11 \mathrm{a}$ & $5 \mathrm{a}$ & $3 \mathrm{a}$ & $537 \mathrm{a}$ & $135 \mathrm{a}$ & $34 \mathrm{a}$ & $15 \mathrm{a}$ & $9 \mathrm{a}$ \\
\hline 2 & Safrinha & Maio/2003 & $35 \mathrm{~d}$ & $9 \mathrm{~d}$ & $3 \mathrm{~d}$ & $1 \mathrm{~d}$ & $1 \mathrm{~d}$ & $499 \mathrm{a}$ & $125 \mathrm{a}$ & $32 \mathrm{a}$ & $14 \mathrm{a}$ & $8 \mathrm{a}$ \\
\hline 3 & Safra & Novembro/2003 & $29 \mathrm{~d}$ & $8 \mathrm{~d}$ & $2 \mathrm{~d}$ & $1 \mathrm{~d}$ & $1 \mathrm{~d}$ & $329 \mathrm{~b}$ & $83 \mathrm{~b}$ & $21 \mathrm{~b}$ & $10 \mathrm{~b}$ & $6 \mathrm{~b}$ \\
\hline 4 & Safra & Novembro/2004 & $48 \mathrm{c}$ & $12 \mathrm{c}$ & $3 \mathrm{c}$ & $2 \mathrm{c}$ & $1 \mathrm{c}$ & $601 \mathrm{a}$ & $151 \mathrm{a}$ & $38 \mathrm{a}$ & $17 \mathrm{a}$ & $10 \mathrm{a}$ \\
\hline \multirow[t]{4}{*}{5} & Safra & Dezembro/2004 & $79 \mathrm{~b}$ & $20 \mathrm{~b}$ & $5 \mathrm{~b}$ & $3 b$ & $2 \mathrm{~b}$ & $563 \mathrm{a}$ & $141 \mathrm{a}$ & $36 \mathrm{a}$ & $16 \mathrm{a}$ & $9 \mathrm{a}$ \\
\hline & Média & & 71 & 18 & 5 & 2 & 2 & 506 & 127 & 32 & 15 & 8 \\
\hline & \multicolumn{12}{|c|}{-------Número de vagens por planta------- } \\
\hline & Época & Mês/Ano & D5 & D10 & D20 & D30 & D40 & & & & & \\
\hline 1 & Safrinha & Maio/2002 & $181 \mathrm{c}$ & $46 \mathrm{c}$ & $12 \mathrm{c}$ & $6 c$ & $3 \mathrm{c}$ & & & & & \\
\hline 2 & Safrinha & Maio/2003 & $258 \mathrm{~b}$ & $65 \mathrm{~b}$ & $17 \mathrm{~b}$ & $8 \mathrm{~b}$ & $5 \mathrm{~b}$ & & & & & \\
\hline 3 & Safra & Novembro/2003 & $441 \mathrm{a}$ & $111 \mathrm{a}$ & $28 \mathrm{a}$ & $13 \mathrm{a}$ & $7 \mathrm{a}$ & & & & & \\
\hline 4 & Safra & Novembro/2004 & $67 \mathrm{~d}$ & $17 \mathrm{~d}$ & $5 \mathrm{~d}$ & $2 \mathrm{~d}$ & $2 \mathrm{~d}$ & & & & & \\
\hline 5 & Safra & Dezembro/2004 & $54 \mathrm{~d}$ & $14 \mathrm{~d}$ & $4 \mathrm{~d}$ & $2 \mathrm{~d}$ & $1 \mathrm{~d}$ & & & & & \\
\hline & Média & & 200 & 50 & 13 & 6 & 4 & & & & & \\
\hline
\end{tabular}

* Médias não seguidas de mesma letra diferem pelo teste de Scott Knott em nível de 5\% de probabilidade de erro (aproximado). Valores iguais com letras diferentes devido ao arredondamento sem nenhuma casa decimal.

\section{REFERÊNCIAS}

BARBIN, D. Planejamento e análise estatística de experimentos agronômicos. Arapongas: Midas, 2003. 208p.

CARGNELUTti FilHo, A. et al. Tamanho de amostra de caracteres de cultivares de feijão. Ciência Rural, v.38, p.635642, 2008. Disponível em: http://www.scielo.br/ s c i e lo.php? s cript=sci_arttext \& pid=S $0103-$ $84782008000300007 \& \operatorname{lng}=$ pt $\&$ nrm $=$ iso\&tlng=pt. Doi: $10.1590 / \mathrm{S} 0103-84782008000300007$.

CRUZ, C.D. Programa GENES - versão windows. Aplicativo computacional em genética e estatística. Viçosa: UFV, 2001. 648p.

ESTEFANEL, V. et al. Tamanho da amostra para estimar características agronômicas da soja. Revista do Centro de Ciências Rurais, v.14, p.221-229, 1984.

ESTEFANEL, V. et al. Tamanho da amostra para avaliação de componentes do rendimento na cultura do feijoeiro. Ciência Rural, v.26, p.367-370, 1996.
GOMES, F.P. Curso de estatística experimental. 13.ed. Piracicaba, São Paulo: Nobel 1990. 468 p.

LOPES, S.J. et al. Tamanho de parcela para produtividade de grãos de sorgo granífero em diferentes densidades de plantas. Pesquisa Agropecuária Brasileira, v.40, p.525-530, 2005. Disponível em: http://www.scielo.br/scielo.php?script=sci_arttext\&pid=S0100$204 X 2005000600001 \& \operatorname{lng}=$ en\&nrm=iso\&tlng=pt. Doi: 10.1590 / S0100-204X2005000600001.

LORENTZ, L.H. et al. Variação temporal do tamanho de amostra para experimentos em estufa plástica. Ciência Rural, v.34, p.1043-1049, 2004.

LÚCIO, A.D. et al. Classificação dos experimentos de competição de cultivares quanto a sua precisão. Pesquisa Agropecuária Gaúcha, v.5, p.99-103, 1999.

LÚCIO, A.D. et al. Tamanho da amostra e método de amostragem para avaliação de características do pimentão em estufa plástica. Horticultura Brasileira, v.21, p.180-184, 2003 .

Ciência Rural, v.39, n.4, jul, 2009. 
MARODIM, V.S. et al. Delineamento experimental e tamanho de amostra para alface cultivada em hidroponia. Ciência Rural, v.30, p.779-781, 2000 .

MARTIN, T.N. et al. Bases genéticas de milho e alterações no plano experimental. Pesquisa Agropecuária Brasileira v.40, p.35-40, 2005a. Disponível em: http://www.scielo.br/ scielo.php? script=sci_arttext \& pid = S $0100-$ 204X2005000100005\&lng=en\&nrm=iso\&tlng=pt. Doi: 10.1590/S0100-204X2005000100005.

MARTIN, T.N. et al. Metodologia experimental para rendimento de grãos de soja em condições de restrição de espaço. Bragantia, v.66, p.521-526. 2007. Disponível em: http:// www.scielo.br/scielo.php?script $=$ sci arttext\&pid $=$ S0006$87052007000300020 \& \operatorname{lng}=\mathrm{en} \& \mathrm{nrm}=\overline{\mathrm{is}} \mathrm{\alpha}$ t $\operatorname{lng}=\mathrm{pt}$. Doi $10.1590 / \mathrm{S} 0006-87052007000300020$.

MARTIN, T.N. et al. Plano amostral em parcelas de milho para avaliação de atributos de espigas. Ciência Rural, v.35, p.1257-1262, 2005b.

MARTIN, T.N. et al. Tamanho ótimo de parcela e número de repetições em soja (Glycine max (L.) Merril). Ciência Rural, v35, p.271-276, $2005 \mathrm{c}$.

PALOMINO, E.C. et al. Tamanho da amostra para avaliação de famílias de meios-irmãos de milho. Pesquisa Agropecuária
Brasileira, v.35, n. 7, p.1433-1439, 2000. Disponível em: http:/ /www.scielo.br/scielo.php?script $=$ sci arttext\&pid $=\mathrm{S} 0100$ 204X2000000700018\&lng=en\&nrm=iso\&tlng=pt. Doi: $10.1590 /$ S0100-204X2000000700018.

RAMALHO, M.A.P. et al. Experimentação em genética e melhoramento de plantas. Lavras: UFLA, 2000. 326p.

SILVA, P.S.L. et al. Sample size for the estimation of some sorghum traits. Revista Brasileira de Milho e Sorgo, v.4, p.149-160, 2005 .

SOUZA, M.F. et al. Tamanho da amostra para peso da massa de frutos, na cultura da abóbora italiana em estufa plástica. Agrociência, v.8, p.123-128, 2002.

STORCK, L. et al. Comparação de métodos de estimativa do índice de heterogeneidade do solo e do tamanho ótimo de parcela em experimento com soja. Revista do Centro de Ciências Rurais, v.12, p.189-202, 1982.

STORCK, L. et al. Experimentação vegetal. 2.ed. Santa Maria: UFSM, 2006. 198p.

STORCK, L. et al. Sample size for single, double and three-way hybrid corn ear traits. Scientia Agricola, v.64, p.30-35, 2007. 